\title{
ANALISIS PENGENDALIAN INTERNAL ATAS PERSEDIAAN BARANG DAGANG PADA TOKO ALFAMART
}

\author{
Rika Regina \\ Universitas Muhammadiyah Sukabumi \\ Email: rikaregina07@gmail.com
}

\section{Artikel info \\ Artikel history: \\ Received : 07-09-2020 \\ Revised : 15-09-2020 \\ Approved : 20-09-2020}

\section{Kata Kunci:}

Pengendalian Internal, Persediaan Barang Dagang, internal cotrol, merchandise inventory,
Abstrak: Penelitian ini bertujuan untuk mengetahui: 1) Penerapan Pengendalian Internal yang diterapkan oleh perusahaan pada Toko Alfamart. 2) Peranan Pengendalian Internal Terhadap Persediaaan Barang Dagang pada Toko Alfamart. 3) Kendala dan Solusi dalam menerapkan Pengendalian Internal Persediaan Barang Dagang pada Toko Alfamart. Variabel terdiri dari Pengendalian sebagai variabel independen, variabel Persediaan sebagai variabel dependen. Metode peneltian yang digunakan adalah metode kualitatif dengan pendekatan deskriptif. Penelitian ini dilakukan dengan menggunakan teknik observasi dan wawancara dengan pihak-pihak yang terlibat Pengendalian Persediaan Barang Dagang. Hasil dari penelitian ini adalah bahwa pengendalian internal atas persediaan barang yang mencakup lingkungan pengendalian, penilaian risiko, aktivitas pengendalian, informasi dan komunikasi, dan monitoring sudah berjalan dengan baik. Namun mengenai kedisiplinan karyawan toko alfamart masih adanya yang tidak mematuhi aturan sehingga menghambat kepada proses pengendalian internal atas persediaan barang dagang.

\section{Koresponden author: Rika Regina}

Email: rikaregina07@gmail.com artikel dengan akses terbuka dibawah lisensi

CC BY SA 2020

\section{PENDAHULUAN}

Dalam era globalisasi Indonesia merupakan salah satu negara berkembang sehingga industri-insdustri perusahaan mampu bersaing dengan negara lain terutama dalam perusahaan dagang seperti minimarket Alfamart. Pada suatu perusahaan tersebut pasti mempunyai tujuan yang sama yaitu mewujudkan rencana perusahaan agar mendapatkan suatu laba, sehingga mampu mengembangkan perusahaan nya menjadi lebih baik. Salah satu unsur yang paling aktif dalam pengembangan perusahaan yaitu persediaan. Persediaan Barang dalam bentuk siap dijual kembali dan yang paling aktif dalam operasi usahanya merupakan Aktiva (Shatu, 2016:136).

Serangkaian kebijakan pengendalian untuk menentukan tingkat persediaan yang harus dijaga merupakan Sistem pengelolaan persediaan. Apabila jumlah persediaan tersebut terlalu besar (overstock) mengakibatkan timbulnya dana menganggur yang besar, juga menimbulkan risiko kerusakan barang yang lebih besar dan penyimpanan yang tinggi. Dan jika persediaan barang tersebut kurang maka akan mengakibatkan kebutuhan-kebutuhan konsumen tidak akan terpenuhi. 
Aktiva yang sangat penting didalam perusahaan yaitu persediaan, sehingga adanya beberapa fungsi sistem internal control terhadap persediaan, yaitu: (1). Internal control terhadap pencegahan persediaan, karena persediaan mudah dipindah tempatkan dari kerawanan lainnya. (2). Internal control terhadap pencatatan persediaan sebagai laporan barang dan bukti serta pemakaian persediaan yang siap dijual yang sementara masih ada dalam gudang. (3). Internal control atas jumlah persediaan. Hal tersebut dibutuhkannya pengelolaan pengendalian internal persediaan untuk mencegah terjadinya kecurangan. Pengendalian internal merupakan suatu sistem yang meliputi struktur organisasi beserta semua mekanisme dan ukuran-ukuran yang dipatuhi bersama untuk menjaga seluruh harta kekayaan organisasi dari berbagai arah (Dr. Mardi, 2016).

Penelitian ini bertujuan untuk mengetahui: 1) Penerapan Pengendalian Internal yang diterapkan oleh perusahaan pada Toko Alfamart. 2) Peranan Pengendalian Internal Terhadap Persediaaan Barang Dagang pada Toko Alfamart. 3) Kendala dan Solusi dalam menerapkan Pengendalian Internal Persediaan Barang Dagang pada Toko Alfamart. Maka peneliti tertarik untuk melakukan penelitian yng tertuang dalam judul "Analisis Pengendalian Internal atas Persediaan Barang Dagang pada Toko Alfamart"

a. Kerangka Teoritis

1) Pengendalian Internal

Pengendalian internal merupakan suatu sistem yang meliputi struktur organisasi beserta semua mekanisme dan ukuran-ukuran yang dipatuhi bersama untuk menjaga seluruh harta kekayaan organisasi dari berbagai arah (Mardi : 2016).

Lebih lanjut, Pengendalian internal merupakan seperangkat kebijakan dan prosedur untuk melindungi asset atau kekayaan perusahaan dari segala bentuk tindakan penyalahgunaan, menjamin tersedianya informasi akuntansi perusahaan yang akurat, serta memastikan bahwa semua ketentuan (peraturan) hukum/undang-undang serta kebijakan manajemen telah dipatuhi atau dijalankan sebagaimana mestinya oleh seluruh karyawan perusahaan (Hery : 2014).

2) Persediaan Barang Dagang

Persediaan merupakan asset yang tersedia untuk dijual dalam kegiatan usaha biasa, dalam proses produksi untuk penjualan tersebut atau dalam bentuk bahan atau perlengkapan untuk digunakan dalam proses produksi atau pemberian jasa (PSAK No 14 : 2013).

Persediaan merupakan salah satu asset yang sangat penting bagi suatu entitas baik bagi perusahaan ritel, manufaktur, jasa, maupun entitas lainnya (Martani et.al : 2016).

Berdasarkan pengertian diatas dapat dipahami bahwa pada intinya persediaan adalah barang milik perusahaan untuk dijual kembali dalam kegiatan usahanya, barang-barang yang masih dalam proses produksi atau bahan-bahan yang akan digunakan dalam proses produksi.

\section{METODE PENELITIAN}

Metode yang digunakan penelitian dalam menganalisis, menggunakan metode kualitatif. Pendekatan metode kualitatif yang diambil merupakan pendekatan deskriptif. Pendekatan deskriptif ini, data yang diamati berbentuk kata-kata dan gambar, tidak menggunakan data berbentuk angka. Metode kualitatif ini diyakini dapat menganalisis pengendalian internal atas persediaan barang dagang pada toko Alfamart Fatmawati 6, Alfamart Madrasah 2 dan Alfamart H.Nawi 2 Jakarta Selatan. 
Informan dalam penelitian ini adalah terdiri dari :

1. Pejabat Toko

2. Crew

\section{HASIL DAN PEMBAHASAN}

Penerapan Pengendalian Internal atas Persediaan Barang Dagang khususnya : Toko Alfamart Fatmawati 6, Toko Madrasah 2, Toko H.Nawi 2 Jakarta Selatan:

Pengendalian Internal Persediaan Barang Dagang

\section{Lingkungan Pengendalian}

a. Lingkungan Pengendalian Toko Alfamart Fatmawati 6

Dalam hal ini semua karyawan ditekankan untuk bertindak dan bersikap jujur kepada konsumen, pemasok dan semua pihak yang berhubungan dengan perusahaan. Selain itu, adanya struktur organisasi yang merupakan salah satu bentuk lingkungan pengendalian yang ada di toko Alfamart Fatmawati 6 yang menggambarkan tugas yang jelas baik menyangkut wewenang, tanggung jawab, fungsi maupun hubungan organisasi.

b. Lingkungan Pengendalian Toko Alfamart Madrasah 2

Lingkungan pengendalian yang ada di toko Alfamart Madrasah 2 sehingga setiap karyawan akan bekerja sesuai dengan bagian dan tugasnya seperti yang tercantum dalam uraian tugas termasuk bagian yang terlibat dalam penerimaan, pengeluaran dan pemeriksaan fisik persediaan dagang. Struktur organisasi menggambarkan tugas yang jelas baik menyangkut wewenang, tanggung jawab, fungsi maupun hubungan organisasi. Adapun pembagian tugasnya terdiri dari, tugas kepala toko, asisten kepala toko, pramuniaga dan kasir.

c. Lingkungan Pengendalian Toko Alfamart H.Nawi 2

Struktur organisasi menggambarkan tugas yang jelas baik menyangkut wewenang, tanggung jawab, fungsi maupun hubungan organisasi. Adapun pembagian tugasnya terdiri dari, tugas kepala toko, asisten kepala toko, pramuniaga dan kasir. Adapun untuk mencapai tujuan perusahaan Toko Alfamart H.Nawi 2 meningkatkan pelayanan yang ditawarkan kepada pelanggan seperti pengisian pulsa telepon seluler, pulsa listrik, membayar listrik dan lain-lain. 2. Penilaian Risiko

\section{a. Penilaian Riiko Toko Alfamart Fatmawati 6}

Barang dagang yang ada ditoko Alfamart Fatmawati 6 Jakarta Selatan terdiri dari produkproduk food dan non food. Khususnya produk food yang biasa dikonsumsi seperti makanan, minuman, obat-obatan dan sebagainya perlu diperhatikan masa kadaluwarsanya. Jika telah memasuki masa kadaluwarsa (expired) maka produk makanan tersebut tidak akan dijual kepada konsumen. Untuk mengatasi hal tersebut maka produk-produk makanan dan sejenisnya yang memiliki batas kadaluwarsa (expired) harus segera ditarik dari area penjualan untuk diretur ke gudang (warehouse).

b. Penilaian Risiko Toko Alfamart Madrasah 2

Toko Alfamart Madrasah 2 Jakarta Selatan, terdiri dari produk makanan, minuman dan lainnya yang biasa dikonsumsi sangat diperhatikan dan dicek masa kadaluwarsanya. Adapun penilaian risiko yang dilakukan, yaitu karyawan melakukan penarikan produk-produk yang sudah mendekati kadaluarsa ataupun rusak dari area penjualan untuk diretur kegudang. Untuk meminimalkan atau menantisipasi risiko-risiko tersebut perusahaan melakukan evaluasi dan perbaikan-perbaikan atas pengendalian internal yang telah berjalan jika terdapat kelemahan termasuk kebijkan-kebijakan atau peraturan-peraturan yang ada. 


\section{c. Penilaian Risiko Toko Alfamart H.Nawi 2}

Produk-produk food dan non food. Khususnya produk food yang biasa dikonsumsi seperti makanan, minuman, obat-obatan dan sebagainya perlu diperhatikan masa kadaluwarsanya. Jika telah memasuki masa kadaluwarsa (expired) maka produk makanan tersebut tidak akan dijual kepada konsumen. Untuk mengatasi hal tersebut maka produk-produk makanan dan sejenisnya yang memiliki batas kadaluwarsa (expired) harus segera ditarik dari area penjualan untuk diretur ke gudang (warehouse). Penarikan tersebut dilakukan pada saat melakukan stock opname atau pemeriksaan fisik barang dagang sehingga dapat mengurangi resiko-resiko yang akan terjadi.

\section{Aktivitas Pengendalian}

\section{a. Aktivitas Pengendalian Toko Fatmawati 6}

Operasional toko alfamart fatmawati 6 berlangsung 16 jam perhari dengan pembagian kerja sebanyak 2 shift yaitu shift pertama dimulai pukul 06.00 WIB sampai pukul 16.00 WIB. Sedangkan shift kedua dimulai pukul 14.00 WIB sampai 22.00 WIB, dalam setiap shift yang bertugas terdapat dua karyawan yaitu pejabat toko dan satu crew. Selain itu, aktivitas pengendalian yang terjadi pada alfamart fatmawati 6 dimulai dengan adanya pengiriman barang dari gudang yang diangkut menggunakan truk khusus barang kemudian pejabat toko dan crew yang bertugas pada shift saat barang dagangan sampai ketoko melakukan penurunan barang, pengecekan barang sesuai dengan rincian yang tertera pada faktur lalu di file dan disimpan ke dalam ordner.

\section{b. Aktivitas Pengendalian Toko Alfamart Madrasah 2}

Aktivitas pengendalian yang dilakukan pada toko madrasah Jakarta selatan yaitu pengecekan fisik barang atau SO harian yang ada dirak dilakukan setiap hari oleh pejabat toko atau crew yang bertugas sehingga barang-barang tersebut dalam keadaan baik dan tidak ada yang expired. Adapun Operasional toko alfamart Madrasah 2 berlangsung 16 jam perhari dengan pembagian kerja sebanyak 2 shift yaitu shift pertama dimulai pukul $06.00 \mathrm{WIB}$ sampai pukul 16.00 WIB. Sedangkan shift kedua dimulai pukul 14.00 WIB sampai 22.00 WIB, dalam setiap shift yang bertugas terdapat dua karyawan yaitu pejabat toko dan satu crew.

\section{c. Aktivitas Pengendalian Toko Alfamart H.Nawi}

Operasional toko alfamart H.Nawi 2 berlangsung 24 jam perhari dengan pembagian kerja sebanyak 3 shift yaitu shift pertama dimulai pukul 06.00 WIB sampai pukul 16.00 WIB. Sedangkan shift kedua dimulai pukul 14.00 WIB sampai 22.00 WIB, dan shift ketiga yaitu pada pukul 22.00 WIB- 07.00 WIB. Dalam setiap shift yang bertugas terdapat dua karyawan yaitu pejabat toko dan satu crew. aktivitas pengendalian yang dilakukan pada toko $\mathrm{H}$. Nawi Jakarta selatan yaitu pengecekan fisik barang atau SO harian yang ada dirak dilakukan setiap hari oleh pejabat toko atau crew yang bertugas sehingga barang-barang tersebut dalam keadaan baik dan tidak ada yang expired.

4. Informasi dan Komunikasi

a. Informasi dan Komunikasi Toko Alfamart Fatmawati 6

Sistem informasi dan komunikasi yang dilakukan di toko Alfamart Fatmawati 6 Jakarta selatan yaitu dari adanya penggunaan alat yang dinamakan PDA (Personal Daily Activity) yang memudahkan karyawan melakukan Stock Opname, mengecek penerimaan barang, membuat harga, namun kadang kala dalam membuat harga adanya kesalahan karyawan yang telat menyesuaikan harga-harga yang tertera dirak degan harga yang ada pada sistem. 
Selain itu juga adanya tablet yang digunakan pengecekan ketersediaan barang dagang, tatanan barang di rak atau planogram agar tidak perlu melihat dikomputer. Dengan adanya sistem tersebut maka sangat mendukung pada pencapaian tujuan perusahaan.

b. Informasi dan Komunikasi Toko Alfamart Madrasah 2

Dalam informasi dan komunikasi toko Alfamart Madrasah yaitu dilakukannya briefing setiap pagi oleh pejabat toko sebelum melakukan operasional toko. Selanjutnya ada serah terima antar pejabat toko yang bertugas mengenai pemegang kunci berangkas, pembukaan dan penutupan transaksi kasir pada saat pergantian shift. Penggunaan alat yang dinamakan PDA (Personal Daily Activity) yang memudahkan karyawan melakukan Stock Opname, mengecek penerimaan barang, membuat harga, dan adanya tablet yang digunakan pengecekan ketersediaan barang dagang, tatanan barang di rak atau planogram agar tidak perlu melihat dikomputer.

c. Informasi dan Komunikasi Toko Alfamart H.Nawi 2

Informasi dan komunikasi toko Alfamart H.Nawi 2 yaitu dilakukannya briefing setiap pagi oleh pejabat toko sebelum melakukan operasional toko. Selanjutnya ada serah terima antar pejabat toko yang bertugas mengenai pemegang kunci berangkas, pembukaan dan penutupan transaksi kasir pada saat pergantian shift. Kemudian pejabat toko mencetak laporan penjualan kasir dan scara rutin melaporkan nilai penjualan harian kepada korwil pada saat malam hari yang dikenal dengan istilah EOD (End Off Day). Selain itu, adanya penggunaan alat yang dinamakan PDA (Personal Daily Activity) dan Tablet untuk memudahkan karyawan.

\section{Monitoring}

a. Monitoring Toko Alfamart Fatmawati 6

Monitoring yang dilakukan oleh pejabat toko (kepala toko dan asisten kepala toko) alfamart Fatmawati 6 sudah berjalan baik, dimana pejabat toko melakukan pengecekan persediaan barangg yang ditugaskan dalam setiap shift dengan rutin melakukan SO harian. Selain itu, monitoring yang dilakukan oleh koordinator wilayah (Area Coordinator) sudah berjalan cukup baik, yaitu dengan melakukan kunjungan rutin yang sudah terjadwal dan secara berkala ketoko-toko yang berada dibawah areanya.

b. Monitoring Toko Alfamart Madrasah 2

Pada alfamart Madrasah 2 monitoring yang sudah dilakukan telah berjalan baik. Dimana monitoring yang dilakukan oleh pejabat toko yaitu pengecekan persediaan barang yang ditugaskan dalam setiap shift dan dengan rutin melakukan SO harian. Selain itu, monitoring yang dilakukan oleh koordinator wilayah (Korwil) sudah berjalan cukup baik, yaitu dengan melakukan kunjungan rutin yang sudah terjadwal dan secara berkala ketoko-toko yang berada dibawah areanya.

c. Monitoring Toko Alfamart H.Nawi 2

Pejabat toko melakukan pengecekan persediaan barangg yang ditugaskan dalam setiap shift dengan rutin melakukan SO harian. Selain itu, monitoring yang dilakukan oleh koordinator wilayah (Area Coordinator). Tanpa adanya monitoring maka aktivitas pengendalian barang dagang tidak akan berjalan dengan baik. 


\section{KESIMPULAN}

Berdasarkan hasil penelitian yang tertuang dari pembahasan, maka dapat ditarik kesimpulan akhir dari penelitian Analisis Pengendalian Internal atas Persediaan Barang Dagang pada Toko Alfamart Fatmawati 6 Jakarta Selatan, Toko Alfamart Madrasah 2 Jakarta Selatan, Toko Alfamart H. Nawi 2 Jakarta Selatan adalah sebagai berikut: 1) Penerapan Pengendalian Internal yang diterapkan perusahaan mengenai Persediaan Barang Dagang terhadap Toko Alfamart Fatmawati 6 Jakarta Selatan, Toko Alfamart Madrasah 2 Jakarta Selatan dan Toko Alfamart H.Nawi 2 Jakarta Selatan sejauh ini sudah diterapkan dengan baik. Hal ini dibuktikan dengan adanya Standar Operasional Prosedur(SOP) yang diterapkan terhadap Toko-toko Alfamart. 2)Peranan Pengendalian internal atas persediaan barang dagang pada Toko Alfamartfatmawati 6 Jakarta Selatan, Toko Alfamart Madrasah 2 Jakarta Selatan dan Toko Alfamart H.Nawi 2 Jakarta Selatan sudah berjalan cukup baik. Kendala dan solusi dalam menerapkan pengendalian internal atas persediaan barang dagang terhadap toko alfamart Fatmawati 6 Jakarta Selatan, toko alfamart madrasah 2 Jakarta Selatan dan toko alfamart H.Nawi 2 Jakarta Selatan yaitu masih adanya karyawantoko yang tidak menjalankan tugasnya dengan baik sehingga dapat menghambat pada proses pengendalian internal atas persediaan barang. Solusi yang dilakukan toko terhadaphal tersebut yaitu dengan dilakukannya briefing setiap pagi oleh pejabat toko. 


\section{Bibliografi}

Akuntansi Manajemen: Informasi biaya untuk mengendalikan aktivitas operasi dan informasi. 2013.

Amanda T Sambara. (2018). Analisis pengendalian internal atas persediaan barang dagang pada PT. XYZ. Skripsi. Yogyakarta: Universitas Sanata Darma

Amanda, Chyntia. Jullie J, Sondakh dan Steven J, Tangkuman. (2015). Analisis evektifitas system pengendalian internal atas persediaan barang dagang pada Grand Hardware Manado. Vol.3 No.3 Sept.2015. Hal 766.

Binanggal, Chansie Virji. 2016. Analisis sistem pengendalian internal piutang pada PT. Tunas Dwipa Marta cabang Manado. Jurnal EMBAVol.4 No.3 September 2016. Hal 147-155. Fakultas ekonomi dan Bisnis. Universitas Sam Ratulangi Manado.

Dr. Mardi. (2017). Sistem Informasi Akuntansi. Bogor: Graha Indonesia

Dasandra V. Rama dan Jones L. Frederick (2008). Sistem Informasi Akuntansi Edisi 18. Jakarta: Salemba Empat.

Hery. 2014. Pengendalian Akuntansi dan Manajemen. Edisi pertama. Jakarta: Kencana.

Hery. (2014). Pengendalian Akuntansi dan Manajemen. Edisi pertama. Jakarta: Prenada media Grup.

Hery. (2016). Akuntansi: aktiva, utang dan modal. Edisi kedua, cetakan kesatu. Yogyakarta: Gava Media.

Hery. Akuntansi Jasa dan Dagang : praktis dengan contoh soal. Cetakan kesatu. Yogyakarta: Gava Media.

Jusup, Al. Haryono. (2011). Auditing: pengauditan berbasis ISA (International Standards on Auditing). Jakarta: Salemba Empat.

Mu'minin, ummil. 2015. Analisis pengendalian internal atas persediaan barang dagang. Studi kasus di distribution centre cabang Bekasi. Skripsi. Jakarta: Universitas Darma Persada.

Oktamia, R. U. (2015). Penerapan sistem pengendalian internal persediaan barang dagang pada minimarket Alfamart sumpah pemuda Palembang. Vol.8 No. 1 Ed. Januari - Juni 2019.

Oktaviani, M. Kapoh. Dkk. 2017. Analisis pelaksanaan sistem pengendalian internal pada inspektorat Kabupaten Minahasa Utara. Manado: Universitas Sam Ratulangi.

Rista. 2017. Analisis pengendalian persediaan pada CV. Inar Utama pusat Samarinda. Skripsi. Samarinda: Universitas Mukawarman fakultas ekonomi dan bisnis.

Rizal, effendi. 2015. Accounting principles: prinsip-prinsip Akuntansi berbasis SAK ETAP. Edisi revisi cetakan kedua. Jakarta: Rajawali pers. 
Rizal, effendi. 2015. Accounting principles: prinsip-prinsip Akuntansi berbasis SAK ETAP. Jakarta: PT. Rajagrafindo Persada.

Sugiyono. (2017). Metode Penelitian Kuantitatif, Kualitatif dan $R \& D$. Bandung: Alfabeta.

Seredei, Srijanti dan Runtu Treesje. (2015). Evaluasi penerapan pengendalian internal atas persediaan barang dagang pada PT.Suramando (Distributor Farmasi dan general supplier) di Manado. Vol 3 No.2 Juni 2015, Hal 385-394.

TIMbooks. 2015. Sistem informasi Akuntansi. Jakarta : Salemba Empat.

Tuanakotta, Theodorus M. 2014. Audit berbasis ISA (Interbnational Standards on Auditing). Jakarta : Salemba Empat.

Tontoli, S. Amanah. Inggriani Elim dan Victorina, Z. Tirayoh. (2017). Analisys of effectiveness of internal inventory goods control trade in PT. Kimia farma apotek 74 Manado. Jurnal reset going concern 12(2), 2017, 231-240. Tambara, T. Amanda. (2018). Analysis of internal control on merchandise inventory.

Yayah, P. Shatu. (2016). Akuntansi Perkantoran. Pustaka Ilmu Semesta. www.corporate alfamart.com 